\title{
Institutional National Research Service Award
}

National Cancer Institute

\section{Source}

National Cancer Institute. Institutional National Research Service Award. NCI Thesaurus.

Code C18854.

National Research Service Award (NRSA) institutional training grants (T32) enable elig ible institutions to develop or enhance predoctoral and postdoctoral research training opportunities for individuals, selected by the institution, who are training for careers in specified shortage areas of biomedical and behavioral research. The purpose of the NRSA program is to help ensure that highly trained scientists are available in adequate numbers and in the appropriate research areas and fields to carry out the nation's biomedical and behavioral research agenda. (National Research Service Award Institutional Research Training Grants, NIH Guide, Volume 23, Number 21, June 3, 1994) 